\title{
Seasonal Prevalence of Species of Binucleate Rhizoctonia Fungi in Growing Medium, Leaf Litter, and Stems of Container-Grown Azalea
}

Warren E. Copes, Agricultural Research Service (ARS) Southern Horticulture Laboratory, Poplarville, MS 39470; Marianela
Rodriguez-Carres, Department of Plant Pathology, Center For Integrated Fungal Research, North Carolina State University, Raleigh
27695; Takeshi Toda, Akita Prefectural University, Akita, Japan; Tim A. Rinehart, ARS Southern Horticulture Laboratory; and Marc A. Cubeta, Department of Plant Pathology, Center For Integrated Fungal Research, North Carolina State University

\begin{abstract}
Copes, W. E., Rodriguez-Carres, M., Toda, T., Rinehart, T. A., and Cubeta, M. A. 2011. Seasonal prevalence of species of binucleate Rhizoctonia fungi in growing medium, leaf litter, and stems of container-grown azalea. Plant Dis. 95:705-711.

Rhizoctonia web blight is an annual problem on container-grown azalea (Rhododendron spp.) in the southern and eastern United States but little is documented about the distribution or persistence of Rhizoctonia spp. in container-grown azalea. Sixty web-blight-damaged azalea plants ('Gumpo White') were collected in August 2005 and 2006 and arranged in a completely randomized design on an outdoor irrigation pad. A nylon mesh bag containing 30 necrotic leaves collected from web-blight-damaged 'Gumpo White' azalea plants were placed on the surface of the medium under the plant canopy in each container to simulate leaf litter. Ten plants were destructively sampled into eight zones by dividing stems into three zones (lengths of 0 to 2,4 to 6 , and 9 to $15 \mathrm{~cm}$ above the medium surface), bagged leaves into one leaf litter zone, and the medium into four zones (three horizontal layers: 1 to 3,3 to 7 , and 7 to $10 \mathrm{~cm}$ below the medium surface, with the middle layer further divided by removing the central $7.5-\mathrm{cm}$ diameter core) in December, February, and May. Only the three stem zones were sampled from 10 plants in early and late June and late July. Of 8,940 total isolations, 3,655 fungi with morphological characteristics of a Rhizoctonia sp. were recovered. Percent recovery differed

from the eight zones $(P<0.0001)$ but did not differ between years $(P=$ $0.3950)$ and sampling times $(P=0.1896)$. Frequency of recovery of Rhizoctonia spp. was highest from the lower stem and the leaf litter, and decreased with distance from the leaf litter. Recovery from stems over the six sample times was analyzed separately. Percent recovery differed between stem zones $(P<0.0001)$, sample times $(P=0.0478)$, and experiment years $(P<0.0001)$. In both years, mean recovery of Rhizoctonia spp. was higher from the lower stem and decreased with distance to the upper stem layer. From a subsample of 145 isolates, 95.1\% were identified as binucleate Rhizoctonia (BNR) anastomosis groups (AGs)-A, - G, $-\mathrm{K},-\mathrm{R},-\mathrm{S}$, and $-\mathrm{U}(-\mathrm{P})$, and 2.8 and $2.1 \%$ were Rhizoctonia solani AG-2 and an uncultured Laetisaria sp., respectively. Based on frequency analysis, recovery of BNR AGs differed by plant zone $(P<0.0001)$ but not over sample times $(P=0.4831)$. The six AGs of BNR are the predominant Rhizoctonia fungi occupying the habitat niches in container-grown azalea, with little change in population frequency and composition from fall to summer; thus, BNR pathogenic and nonpathogenic to azalea have established a mixed Rhizoctonia community on container-grown azalea.
\end{abstract}

Web blight of azalea (Rhododendron spp. L.) is an annual problem in ornamental plant nurseries on evergreen azalea cultivars in the southern and southeastern United States. Onset of obvious symptoms typically occurs in July and, if the plants are not sprayed with a fungicide, disease intensifies through September $(9,10,12)$. Binucleate Rhizoctonia species (BNR) were the primary pathogens associated with web blight in North Carolina (12) and, more recently, Rhizoctonia anastomosis group (AG)-U (AG-P) was the primary casual agent of web blight in Mississippi and Alabama (25).

In the nursery, web blight occurs randomly within cultivar and age groupings of uniform plant stock, referred to as blocks of plants, but regularly across nurseries, being present in nearly all azalea cultivar blocks (W. E. Copes, unpublished data). A similar within-block pattern of spatial distribution was reported in a North Carolina nursery (12). The wide dispersal pattern suggests that either production practices facilitate spread or sanitation practices are not effectively limiting spread or not being properly implemented. The mechanisms resulting in wide dispersal of the pathogen in the azalea inventory have not been investigated.

Corresponding author: W. E. Copes, E-mail: warren.copes@ars.usda.gov

Accepted for publication 13 February 2011.

doi:10.1094/PDIS-11-10-0796

This article is in the public domain and not copyrightable. It may be freely reprinted with customary crediting of the source. The American Phytopathological Society, 2011.
The general mechanisms by which Rhizoctonia solani and BNR spread in agricultural field and row crops are well understood. However, no control practices have been developed to address survival and spread of Rhizoctonia spp. in container-grown nursery plants. Azalea producers rely solely on two to three applications of fungicides during July and August to manage Rhizoctonia web blight. Fungicides effectively prevent symptom development but have not diminished dispersal of the pathogen across nurseries. Copes and Scherm (9) showed that increased spacing between plants does not limit disease development, although plant spacing was the only management practice recommended in extension literature $(3,19)$.

Recovery of Rhizoctonia fungi has been documented for various ornamental plants $(6,22)$ but knowledge of the persistence and distribution in ornamental production sites is not well known. The production cycle from cutting propagation to sales for containergrown azalea is 2 to 4 years. Activity and survival patterns of the pathogen during the 10 months (September to July) when plants do not express disease symptoms may provide insight into additional control methods. We hypothesized that the pathogen survives all year either in direct association with container-grown azalea or in close proximity of the nursery, subsequently being spread back to container-grown plants during the early part of the year. This research focused on diseased container-grown azalea plants to evaluate the overwintering of Rhizoctonia spp., organisms capable of occupying arboreal and subterranean habitats. The objective of this research was to determine recovery frequency of pathogenic BNR (25) from the different zones within the stem and growing medium substrates through the winter to summer seasons, and determine whether AGs of BNR persist in the media or on the plant through winter months. 


\section{Materials and Methods}

Experiment establishment and plant care. In August 2005 and 2006, 70 Rhododendron L. 'Gumpo' ('Satsuki') azalea plants exhibiting 35 to $60 \%$ diseased leaves in 3.8-liter containers were collected from a nursery in Semmes, AL and Lucedale, MS. Plants from these nurseries were arbitrarily intermixed and placed on an outdoor irrigation pad with approximately $25 \mathrm{~cm}$ between branch tips of plants at the Agricultural Research Service Thad Cochran Southern Horticultural Laboratory in Poplarville, MS. Height of plants collected in 2005 and 2006 was approximately 17 and 24 $\mathrm{cm}$, respectively, above the surface of the growing medium. Six sampling periods (December, February, May, early June, late June, and late July) were assigned in a completely randomized block design to 10 plants per sampling period, with plant as a replication. Average onset of severe web blight symptoms occurs mid-July. In late August in 2005 and 2006, diseased leaves were collected and stored in plastic bags at $5^{\circ} \mathrm{C}$. Thirty arbitrarily selected leaves were plated on water agar and Rhizoctonia spp. were recovered from $100 \%$ of the leaves. Additionally, 30 symptomatic leaves were placed in a nylon mesh bag $(6 \mathrm{~cm}$ wide by $12 \mathrm{~cm}$ long $)$ and placed on the growing medium below the plant canopy in each container in October 2005 and 2006. Plants received overhead irrigation as needed and were fertilized with $16 \mathrm{~g}$ of 19-5-8 fertilizer (Osmocote Pro, The Scotts Co., Marysville, OH) per container in May 2006 and 2007.

Sampling protocol. Ten plants were destructively sampled at each sampling period. In December, February, and May, isolations were conducted from eight sampling zones. Stems were divided into three zones by height above the medium surface: 0 to $2 \mathrm{~cm}$ (lower stem zone), 4 to $6 \mathrm{~cm}$ (middle stem zone), and 9 to $15 \mathrm{~cm}$ (upper stem zone). Additional sampling zones included bagged blighted leaves (leaf litter zone) and four zones within the growing medium: top layer ( 0 to $3 \mathrm{~cm}$ ); middle layer $(3$ to $7 \mathrm{~cm}$ ), which was subdivided into an inner 7.5-cm-diameter core and an outer subsection; and a bottom layer ( 7 to $10 \mathrm{~cm}$ ). The aboveground sampling zones were selected to represent a range of relative humidity levels. The leaf litter zone represented blighted leaves that fell during the previous active web blight period and serve as a potential food base (18). The growing medium was hypothesized as the habitat preference of Rhizoctonia spp.; the sampling zones were selected to represent a range of fluctuations in moisture and temperature $(4,15,21,24)$. In early and late June, isolations were made only from the three stem zones and, in late-July, samples were made from the three stem zones and the leaf litter zone, as previously described.

Stems were sampled sequentially from the upper to lower zones. Five stems per zone were selected using a random number sort (Microsoft Excel) and the leaves were stripped off using tweezers.
Forceps and pruners were flame sterilized between cuts. In all, 15 stem sections per plant and 150 per time period (Table 1) were plated on Ko and Hora medium (17), which was modified by substituting mefenoxam (Subdue Maxx at $5 \mu$ liter ${ }^{-1}$ ) for fenaminosulf. In total, 30 leaves per mesh bag were separated and rated for percent degradation; a total of 300 leaves per period were plated on Ko and Hora medium. Fallen leaves and fertilizer pellets were gently scraped off the growing medium surface and discarded. The growing medium was separated into three horizontal layers using a reciprocating saw. The central core of the middle layer was removed with a 7.6-cm-diameter soil auger (AMS, Inc., American Falls, ID). The saw blade and auger were wiped clean and flame sterilized between cuts. Each zone of the growing medium was sorted into three size grades $(>0.56,0.28$ to 0.56 and $<0.28 \mathrm{~mm}$ ) by vigorous manual shaking through $30.5-\mathrm{cm}-$ diameter sieves (nos. 7 and 32). For the growing medium, 21 samples $($ mean $=0.275 \mathrm{~g}$, standard deviation $=0.059 \mathrm{~g})$ per zone, 84 samples per plant, and 840 samples per time period were plated on modified Ko and Hora medium (Table 1).

Plates were incubated in the dark at room temperature $\left(23^{\circ} \mathrm{C}\right)$ and examined daily for 7 days. Mycelium from putative colonies of Rhizoctonia were transferred to half-strength potato dextrose agar (hPDA). Isolates on hPDA were grown at $23^{\circ} \mathrm{C}$ under ambient light in the laboratory for 14 days. Subsequently, pure cultures were maintained on hPDA in a dark growth room at $23^{\circ} \mathrm{C}$ and $30 \%$ relative humidity.

Morphological characterization of isolates. All Rhizoctonia cultures on hPDA were assessed for mycelium color (partly dark brown, partly reddish brown, and entirely tan), percent area of brown color on the underside of the plate, and presence of sclerotia after 28 days of incubation at $23^{\circ} \mathrm{C}$. Frequency tables of these traits were generated per the sample period, per plant, and per zone per plant for the purpose of selecting a subsample of isolates with mycelium colony color and sclerotial incidence traits representative of the Rhizoctonia population recovered per zone and plant at each time period. Subsamples of (i) 80 isolates from the December, February, and May sample periods and (ii) 20 isolates from the June and July sample periods were selected to determine nuclear condition and to be stored. Isolates were grown on pearled barley (28) and stored in 7.6-by-14- $\mathrm{cm}$ manila envelopes at $-20^{\circ} \mathrm{C}$.

For nuclear staining, hyphal tips from 3- to 5-day-old cultures were transferred to water-agar-coated glass slides placed on wet paper towels, sealed in 6.5-by-14.5-by-21-cm clear plastic containers, maintained in darkness at $23^{\circ} \mathrm{C}$ for up to $72 \mathrm{~h}$. Cultures were checked daily. When mycelium had grown across the slide, mycelium was stained with phenosafranin (one drop of $3 \% \mathrm{KOH}$ and a second drop of $0.6 \%$ phenosafranin) and the nuclear condition assessed at $\times 200$ magnification for five arbitrarily selected and spatially separated cells (25).

Table 1. Number of isolations performed to recover Rhizoctonia isolates from eight zones per plant of 10 azalea plants per sample period, for six sample periods per year, in Alabama and Mississippi nurseries for 2 years (December 2005 to July 2007)

\begin{tabular}{|c|c|c|c|c|}
\hline \multirow[b]{2}{*}{ Zone per container } & \multicolumn{3}{|c|}{ Number of isolations per sample period ${ }^{v}$} & \multirow[b]{2}{*}{ Totaly } \\
\hline & Dec-Feb-May ${ }^{w}$ & Early and late June ${ }^{x}$ & Late July ${ }^{x}$ & \\
\hline \multicolumn{5}{|l|}{ Stems } \\
\hline 9 to $15 \mathrm{~cm}$ above medium & $50^{\mathrm{z}}$ & 50 & 50 & 550 \\
\hline 4 to $6 \mathrm{~cm}$ above medium & 50 & 50 & 50 & 600 \\
\hline 0 to $2 \mathrm{~cm}$ above medium & 50 & 50 & 50 & 600 \\
\hline Blighted leaves as leaf litter & 300 & $\mathrm{nsc}$ & 150 & 2,100 \\
\hline \multicolumn{5}{|l|}{ Growing medium } \\
\hline 0 -to-3-cm layer & 210 & $\mathrm{nsc}$ & $\mathrm{nsc}$ & 1,260 \\
\hline Outer band of 3-to-7-cm layer & 210 & $\mathrm{nsc}$ & $\mathrm{nsc}$ & 1,260 \\
\hline Center core of 3-to-7-cm layer & 210 & $\mathrm{nsc}$ & $\mathrm{nsc}$ & 1,260 \\
\hline 7-to-10-cm layer & 210 & $\mathrm{nsc}$ & $\mathrm{nsc}$ & 1,260 \\
\hline
\end{tabular}

${ }^{\mathrm{v}}$ The six sample periods were from 28 November to 9 December 2005 and 1 to 14 February, 1 to 16 May, 9 and 23 June, and 17July 2006 in year 1 and 28

November to 6 December 2006 and 7 to 15 February, 26 April to 3 May, 5 and 16 June, and 19 July 2007 in year 2; nsc $=$ no samples collected.

${ }^{\mathrm{w}}$ December, February, and May. Isolations were completed in 1.5 to 2 weeks per sample period.

${ }^{\mathrm{x}}$ Isolates were completed in 1 to 2 days per sample period.

y Total number of samples per zone.

z Zone not sampled in December 2005. 
DNA sequencing and isolate identification. In all, 145 isolates from 2007 were transferred to hPDA on which a half-sheet of autoclaved P8 filter paper (Fisherbrand, Pittsburgh) had been placed on the agar surface in 100 -mm petri plates. After mycelium colonized the entire plate, mycelium was gently scraped off the filter paper, transferred to sterilized aluminum foil, and frozen at $-20^{\circ} \mathrm{C}$ overnight. Frozen mycelium was ground in a mortar using a pestle. Total genomic DNA was extracted using an UltraClean Soil DNA Extraction Kit (MoBio Laboratories, Carlsbad, CA) and quantified with a Nanodrop spectrophotometer (Thermo Scientific, Wilmington, DE). The internal transcribed spacer (ITS) regions of ribosomal DNA (rDNA) were amplified using polymerase chain reaction (PCR) primers ITS1-F and ITS4-B with cycling conditions described by Gardes and Bruns (13). MasterMix Taq polymerase was used for all reactions according to the manufacturer's recommendations (Eppendorf, Westbury, NY). Amplified products were purified using Qiaquick PCR purification columns (Qiagen, Valencia, CA) and sequenced directly using Big Dye version 3.1 and the ABI3100xl capillary array sequencer (Applied Biosystems, Foster City, CA). Partial sequence data for the ITS regions were generated from primers ITS1, ITS2, ITS3, or ITS4 (13). Single-strand DNA sequence data for ITS1 and ITS2 regions were aligned with reference sequences from GenBank and edited using Sequencher (v. 4.6; Gene Codes Corporation, Ann Arbor, MI). DNA sequences identical to reference sequences or with less than two base differences in the ITS region ( $>97 \%$ identity) were used to classify each isolate to AG.

Based on the above rDNA sequence analysis results, four representative tester isolates of BNR (AG-A, $-\mathrm{K},-\mathrm{R},-\mathrm{S}$, and $-\mathrm{U}$ ) were paired with tester isolates for further characterization using hyphal anastomosis criteria developed by Carling (5). Pairings of each isolate combination were performed at least twice.

Twenty-two isolates were selected to obtain full-length ITS sequences. Fungal isolates were grown in potato dextrose broth for
10 to 14 days. Mycelium was separated from broth by vacuum filtration on autoclaved Whatman no. 1 filter paper, placed in a 50$\mathrm{ml}$ sterile polypropylene storage vial (USA Scientific, Ocala, FL), frozen at $-80^{\circ} \mathrm{C}$ for 6 to $36 \mathrm{~h}$, and lyophilized at $-50^{\circ} \mathrm{C}$ and 0.035 mbar for 3 days (model no. 775508; Labconco Corp., Kansas City, MO). DNA was extracted using a DNeasy plant mini kit (Qiagen Inc., Mississauga, Ontario, Canada), with the modification that 100 $\mu \mathrm{l}$ of glass beads (BioSpec Products, Inc., Bartlesville, OK) was added to each tube along with buffer AP1 and RNase to facilitate lysis of fungal cells. PCRs were prepared in a total volume of $25 \mu \mathrm{l}$ comprising $1 \mu \mathrm{l}$ of extracted DNA, $1 \mu \mathrm{l}$ each of $10 \mu \mathrm{M}$ solutions of ITS1 and ITS4 primers (30) (Integrated DNA Technologies, Coralville, IA), $12.5 \mu \mathrm{l}$ of $2 \times$ PCR master mix (Fermentas, Glen Burnie, MD), and $9.5 \mu$ of DNasefree water (Fermentas) and amplified in an iCycler thermal cycler (Bio-Rad Laboratories, Hercules, CA). Cycle parameters were $96^{\circ} \mathrm{C}$ for $5 \mathrm{~min}$; followed by 30 cycles of $96^{\circ} \mathrm{C}$ for $1 \mathrm{~min}, 55^{\circ} \mathrm{C}$ for $1 \mathrm{~min}$, and $72^{\circ} \mathrm{C}$ for $2 \mathrm{~min}$; followed by 1 cycle of $72^{\circ} \mathrm{C}$ for $7 \mathrm{~min}$; and a final step of cooling at $4^{\circ} \mathrm{C}$. PCR product was stored at $-20^{\circ} \mathrm{C}$. PCR reaction products were purified with the QIAquick PCR purification kit.

The purified PCR product ( $4 \mu \mathrm{l}$ for each isolate) was ligated into a pCR 2.1 vector using the Invitrogen TOPO TA cloning kit (Invitrogen, Carlsbad, CA). Vectors were transformed into One Shot TOP10 chemically competent Escherichia coli (Invitrogen). Three colonies were individually transferred to $4 \mathrm{ml}$ of Luria-Bertani broth and grown at $37^{\circ} \mathrm{C}$ for $24 \mathrm{~h}$. Transformed cultures were centrifuged at 8,000 rpm for $60 \mathrm{~s}$, supernatant was discarded, and the $E$. coli cell pellet was stored at $-20^{\circ} \mathrm{C}$. DNA was extracted from $E$. coli cells using the Invitrogen Purelink Kit and prepared for PCR amplification with the M13 forward and M13 reverse primers (vector map and primer sequences available through Invitrogen) as previously described with ITS1 and ITS4 primers. Amplifications were performed with an iCycler thermal cycler according to Invitrogen's PCR protocol. PCR products were stored in $0.2-\mathrm{ml}$

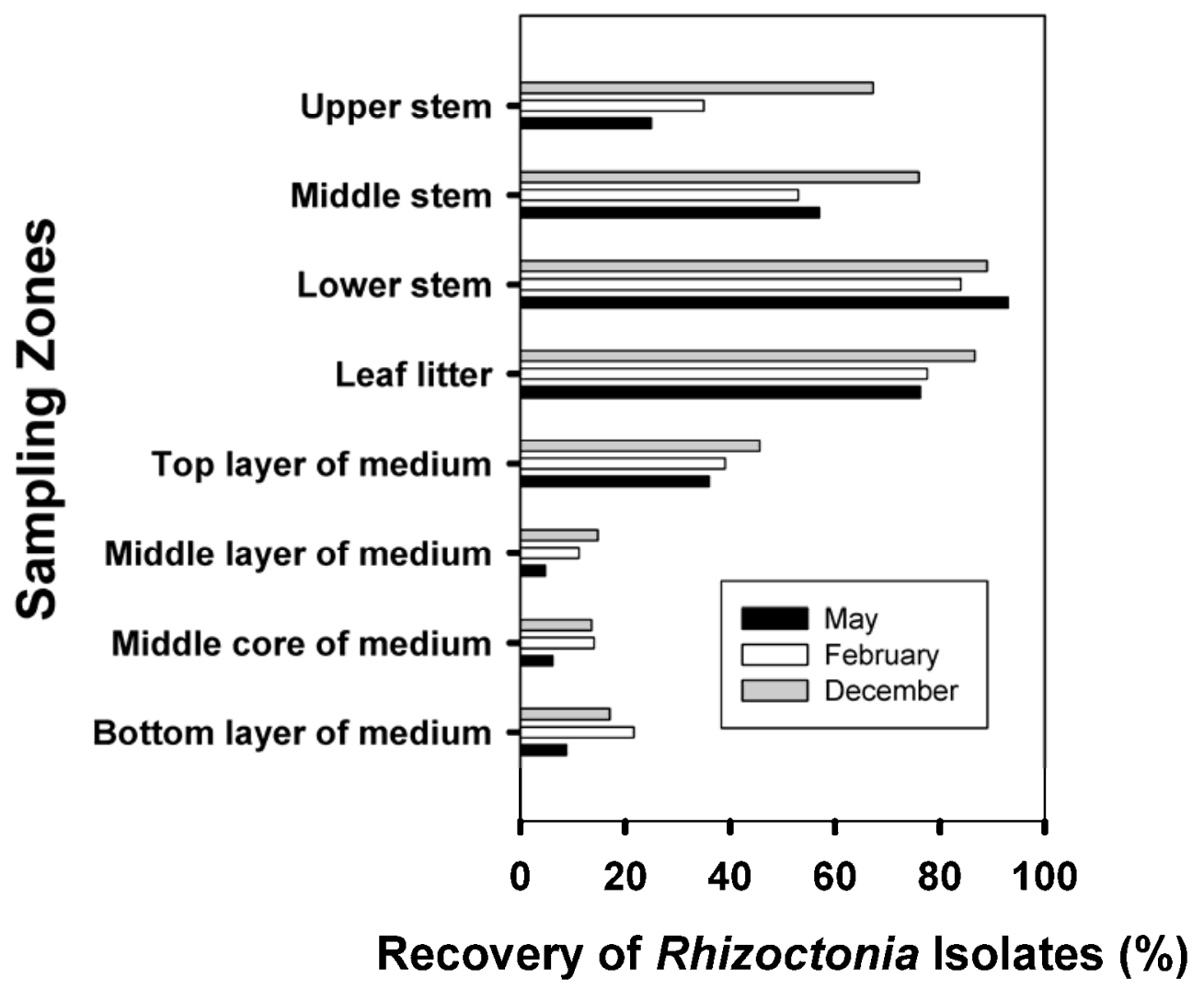

Fig. 1. Mean recovery of total Rhizoctonia spp. from December 2005 to May 2007 from 3.8-liter container-grown 'Gumpo' azalea during early December (gray), early February (white), and early May (black) from three stem zones ( 9 to $15 \mathrm{~cm}$ [upper], 4 to $6 \mathrm{~cm}$ [middle], and 0 to $2 \mathrm{~cm}$ [lower] above the growing medium), one leaf litter zone (leaf litter), and four growing medium zones (1 to $3 \mathrm{~cm}$ [top layer]; 3 to $7 \mathrm{~cm}$ [middle outer layer], which was further divided by extracting a 7.5-cm-diameter core [middle core]; and 7 to $10 \mathrm{~cm}$ [bottom layer] below the medium surface). 
flat-cap tubes at $4{ }^{\circ} \mathrm{C}$. Amplification products were resolved on $1.5 \%$ electrophoresis agarose gels and visualized. PCR products were sent to Advanced Genetics Technologies Center, University of Kentucky, Lexington. The cloned ITS regions were sequenced using PCR sequencing reaction with Big-dye terminator chemistry.

Statistical analysis. An analysis of variance mixed-model procedure (SAS version 9.1.3) was used to test for differences in recovery of Rhizoctonia fungi with respect to zone (stems, leaf litter, and growing medium), time, and interaction effect of zone and time. Although recovery data were binomial (presence or absence from a zone), data were treated as being normally distributed based on the Central Theorem that large sample sizes tend to be normally distributed. Random model effects were plant within time periods, plant within zones, and the interaction effect between time periods and zones. The general Cochran-Mantel-Hanzen test was used to analyze for general response of mycelium color phenotype in response to plant zone when controlling for experiment year. Categorical analysis was used to analyze the association of AG in response to sample time and plant zone. In both analyses, the division of the 145 isolates into categories resulted in some counts being less than five; as a result, the Fisher exact test was performed in combination with Pearson's $\chi^{2}$ and the likelihood ratio $\chi^{2}$.

\section{Results}

In total, 3,655 isolates with morphological characteristics of Rhizoctonia fungi were recovered over the 2-year sampling period. Percent recovery of Rhizoctonia spp. from container-grown plants differed between the eight zones $(P<0.0001)$ but was not different between years $(P=0.3950)$, sample time $(P=0.1896)$, or for zone-sample time interactions $(P=0.9849)$ (Fig. 1). Highest mean recovery $(>80 \%)$ of Rhizoctonia isolates was from the lower stem and leaf litter (Table 2). A moderate mean recovery (40 to 62\%) occurred from the middle and upper stem zones and the top medium layer. Lowest mean recovery $(<16 \%)$ occurred from the middle and bottom medium layers.

Percent recovery of Rhizoctonia spp. from stems across the six sample periods differed significantly between years $(P<0.0001)$ and among the six sample times $(P=0.0478)$ and three sampling zones $(P<0.0001)$ but no interaction occurred between zones and sample time $(P=0.4334)$ (Table 3$)$. Because the 9 - to $15-\mathrm{cm}$ stems were not sampled in December 2005, data for that sample time was excluded from the analysis to maintain a balanced design. In both years, mean recovery of Rhizoctonia spp. was higher from the lower stem and decreased with distance to the upper stem layer. However, differences between adjacent layers differed over time between the 2 years.

The frequency of color on the reverse side of hPDA cultures differed between plant zones when controlling for experiment year (December to July; $P<0.0001$ ) (Table 4). Isolates with a dark

Table 2. Mean percent recovery of total Rhizoctonia spp. from eight zones from 3.8-liter container-grown azalea plants destructively sampled during December, February, and May from December 2005 to July 2007

\begin{tabular}{lc}
\hline Zone & Percent mean recovery $(\mathbf{S E})^{\mathbf{z}}$ \\
\hline Stems & $42.4(8.60) \mathrm{CD}$ \\
9 to $15 \mathrm{~cm}$ above the medium & $62.0(7.42) \mathrm{BC}$ \\
4 to $6 \mathrm{~cm}$ above the medium & $88.7(7.42) \mathrm{A}$ \\
0 to $2 \mathrm{~cm}$ above the medium & $80.2(7.19) \mathrm{AB}$ \\
Blighted leaves placed as leaf litter & $40.2(7.21) \mathrm{D}$ \\
Growing medium & $10.2(7.21) \mathrm{E}$ \\
0-to-3-cm layer & $11.3(7.21) \mathrm{E}$ \\
Outer band of 3-to-7-cm layer & $15.9(7.21) \mathrm{E}$ \\
Center core of 3-to-7-cm layer & \\
7-to-10-cm layer & \\
\hline z Data was combined for experiment years $(P=0.3950)$ and the December, \\
February, and May sampling times $(P=0.1896)$ because probabilities \\
were >0.05. SE = standard error. Zones with the same letter are not \\
significantly different based on pairwise mean separation using mixed \\
analysis of variance procedures.
\end{tabular}

brown phenotype were recovered at a higher frequency than reddish-brown and tan color types from all sample zones for both years. Sclerotia were produced in $36.1,64.6$, and $0.6 \%$ of the brown-, red-, and tan-pigmented cultures, respectively.

Binucleate and multinucleate Rhizoctonia fungi were recovered at a mean (standard deviation) of $88.66 \%$ (7.20\%) and $11.34 \%$ (7.20\%), respectively. Although all isolates had macroscopic mycelium growth patterns and color traits typical of Rhizoctonia spp. on hPDA, a small percentage (actual count not recorded) of the multinucleate isolates had clamp connections; this is not representative of Rhizoctonia fungi but is a trait of some basidiomycetes.

Based on sequence analysis of the rDNA ITS regions of 145 isolates recovered in 2007, seven BNR AGs, one $R$. solani AG-2, and one uncultured Laetisaria sp. were identified (Table 5). Identification based on sequence analysis of the rDNA ITS regions was confirmed with anastomosis pairing with four isolates per BNR AG-A, $-\mathrm{K},-\mathrm{R}$, and $-\mathrm{S}$ and eight isolates per AG-U, where cell wall fusion and cell death resulted only when isolates were paired with the same AG.

In total, 58, 57, 13, and 17 isolates were recovered in February, May, June, and July, respectively. Recovery of AGs did not differ over sample time $(P=0.4831$; Table 6$)$. BNR AG-U was always identified more frequently at each time period than other AGs. For Rhizoctonia AG-G (one during February and one during May) and an uncultured Laetisaria sp. (three during May), recovery frequencies were too low to be included in the analysis. In all, 60, 54, and 31 isolates were recovered from stems, leaf litter, and growing medium, respectively. Recovery of BNR differed among substrates $(P<0.0001$; Table 7). BNR AGs were recovered at similar frequencies from stem and growing medium zones, with AG-U being most frequently recovered. From leaf litter, both AG-U and AG-K were recovered at higher frequencies than the other AGs, and AG-S was not recovered. BNR AG-G (two from growing medium) and an uncultured Laetisaria sp. (three from leaf litter) were recovered at too low of a frequency to be included in the analysis. Darkbrown, reddish-brown, and tan color on the reverse side of hPDA culture plates was evident on 111,8 , and 26 isolates, respectively. All isolates of AG-U, AG-R, and AG-S had brown coloration; all isolates of AG-G and the uncultured Laetisaria sp. and three of four isolates of $R$. solani AG-2 had reddish-brown coloration, and all isolates of AG-A and AG-K had tan coloration. One isolate of $R$. solani AG-2 had brown coloration and, thus, did not neatly fit into a color group. Of the dark-brown pigmented AGs, sclerotia were produced by $77.9,69.2$, and $71.4 \%$ of the AG-U, AG-R, and AG-S

Table 3. Mean percent recovery of total Rhizoctonia spp. from stems at different distances from the growing medium from 3.8-liter containergrown azalea plants

\begin{tabular}{lccc}
\hline & \multicolumn{3}{c}{ Mean recovery (\%) } \\
\cline { 2 - 4 } Sample time & 0 to 2 cm & 4 to 6 cm & $\mathbf{9 ~ t o ~ 1 5 ~ c m ~}$ \\
\hline Year 1 & 80 & 54 & $\mathrm{nsc}$ \\
Early December 2005 & $68 \mathrm{~A}$ & $18 \mathrm{~B}$ & $14 \mathrm{~B}$ \\
Early February 2006 & $88 \mathrm{~A}$ & $34 \mathrm{~B}$ & $24 \mathrm{~B}$ \\
Early May 2006 & $76 \mathrm{~A}$ & $24 \mathrm{~B}$ & $<1 \mathrm{C}$ \\
Early June 2006 & $74 \mathrm{~A}$ & $24 \mathrm{~B}$ & $<1 \mathrm{C}$ \\
Late June 2006 & $94 \mathrm{~A}$ & $64 \mathrm{~B}$ & $10 \mathrm{C}$ \\
Late July 2006 & & & \\
Year 2 & $98 \mathrm{~A}$ & $98 \mathrm{~A}$ & $70 \mathrm{~B}$ \\
Early December 2006 & $100 \mathrm{~A}$ & $88 \mathrm{~A}$ & $56 \mathrm{~B}$ \\
Early February 2007 & $98 \mathrm{~A}$ & $80 \mathrm{~B}$ & $26 \mathrm{C}$ \\
Early May 2007 & $96 \mathrm{~A}$ & $66 \mathrm{~B}$ & $22 \mathrm{C}$ \\
Early June 2007 & $96 \mathrm{~A}$ & $74 \mathrm{~B}$ & $16 \mathrm{C}$ \\
Late June 2007 & $90 \mathrm{~A}$ & $92 \mathrm{~A}$ & $36 \mathrm{~B}$ \\
Late July 2007 & & & \\
\hline
\end{tabular}

${ }^{\mathrm{z}}$ Standard error and degrees of freedom, respectively, were 3.48 and 735 in year 1 and 8.93 and 882 in year 2; nsc = no samples collected for stems at 9 to $15 \mathrm{~cm}$ from the growing media at the first time period and no treatment comparison made. Pairwise comparisons were made between treatments across rows. Recovery was not significantly different between stem sections with the same letter at $P=0.05$. 
isolates, respectively. Of the reddish-brown pigmented AGs, sclerotia were produced by $50.0,33.3$, and $100.0 \%$ of the AG-G, $R$. solani AG-2, and uncultured Laetisaria sp. isolates, respectively. No sclerotia were produced by the tan pigmented AGs (AG-A and AG-K isolates).

\section{Discussion}

At all sampling periods from 2005 to 2007 , BNR colonized the growing medium, senescent blighted leaves on the medium surface, and nonsymptomatic azalea stems. Interestingly, winter did not reduce the recovery of Rhizoctonia spp. that colonize azalea in southern Mississippi, which is in winter hardiness zone $8 \mathrm{~b}$ (1).

Of the 145 isolates characterized, 70.4\% (BNR AG-G, AG-R, AG-S, and AG-U) had been shown previously to cause azalea web blight, whereas $29.6 \%$ (BNR AG-A and AG-K, R. solani AG-2, and an uncultured Laetisaria sp.) were not recovered from symptomatic leaves in a previous study (25). AG-U was the most prevalent AG of BNR in the previous and current studies, representing 92.9 and $57.2 \%$ of the total number of Rhizoctonia isolates recovered, respectively. Although the proportional distribution of BNR AG-G, AG-R, AG-S, and AG-U varied by sampling zone, all were distributed through the entire profile of container-grown azalea plants during winter, spring, and summer seasons. Although the ecological significance of this information is not known, these fungi competitively and persistently colonize stem surfaces and the growing medium of container-grown azalea.

The isolation of BNR that are known causative agents of web blight (25) in the upper canopy of azalea plants throughout the year is problematic. Annual growth of evergreen azalea stems occurs from March to June. Once the current year's stem growth becomes semi-rigid in late May to mid-June, juvenile stems are collected as cuttings for vegetative propagation. We recently estimated that 1 to $15 \%$ of the asymptomatic stems in these nurseries can harbor the pathogen (W. E. Copes, unpublished data). Conditions that favor rooting of azalea stem cuttings-frequent misting and warm temperatures $\left(\geq 25^{\circ} \mathrm{C}\right)$ - are also favorable for growth of BNR. Thus, stem cuttings are a likely source of the web blight pathogen that could result in infestation of the next year's crop. The senior author has observed web blight symptoms on the lower leaves across entire cell trays of rooted azalea plants coming out of commercial propagation houses, and the results of this study show that BNR can persist for at least 1 year in container-grown azalea.

Recovery of AG-A, AG-K, and R. solani AG-2 from nonsymptomatic tissue shows a complex Rhizoctonia community structure within container-grown azalea. Although pathogenicity of AG-A, AG-K, and $R$. solani on azalea was not tested in this study, their absence from symptomatic leaf tissue as reported by Rinehart et al. (25) shows that these AGs are not major causative agents of azalea web blight. Chase (6) found that many BNR were not pathogenic on the ornamental host plant from which they were recovered. Both AG-A and AG-K have previously been recovered from potting soils in ornamental and vegetable nurseries but were not associated with disease (22); both AGs have been shown to be pathogenic on other crops $(11,20,23,26,29,31)$.

The high recovery of BNR from the leaf litter zone, the lower stem, and upper growing medium zone suggests that leaf litter might serve as a food base for Rhizoctonia spp. in container-grown azalea. Fungi in the Rhizoctonia species complex are generally soil inhabiting and can survive for many years as mycelium and sclerotia, often associated with plant debris $(2,14,16,18)$. Additional

Table 4. Contingency table of the melanized mycelium colony color on the reverse side of half-strength potato dextrose agar cultures of species of Rhizoctonia fungi by zones that compose a container-grown azalea

\begin{tabular}{llccc}
\hline & & \multicolumn{2}{c}{ Number of isolates recovered (percent row total) $^{\mathbf{z}}$} \\
\cline { 3 - 5 } Zone & \multicolumn{1}{c}{ Sample period } & Dark brown & Reddish brown & Tan \\
\hline Stems & December 2005 to May 2006 & $295(79.7)$ & $70(18.9)$ & $5(1.4)$ \\
Leaf litter & December 2005 to May 2006 & $683(80.8)$ & $126(14.9)$ & $36(4.3)$ \\
Growing media & December 2005 to May 2006 & $431(72.1)$ & $133(22.2)$ & $34(5.7)$ \\
Stems & December 2006 to May 2007 & $556(87.6)$ & $23(3.6)$ & $56(8.8)$ \\
Leaf litter & December 2006 to May 2007 & $386(53.2)$ & $120(16.6)$ & $219(30.2)$ \\
Growing media & December 2006 to May 2007 & $301(67.0)$ & $120(26.7)$ & $38(8.5)$ \\
Totals & $\ldots$ & $2,652(72.6)$ & $615(16.8)$ & $388(10.6)$ \\
\hline
\end{tabular}

${ }^{\mathrm{z}}$ General Cochran-Mantel-Hansen $\chi^{2}$ value based on rank scores was 130.01 with 4 degrees of freedom for the general association between zone and color on the reverse side of half-strength potato dextrose agar plates $(P<0.0001)$.

Table 5. Classification of binucleate Rhizoctonia anastomosis groups (AGs), Rhizoctonia solani, and an uncultured Laetisaria sp. recovered from stem, dead leaf litter, and pine bark growing medium zones from a container-grown azalea plant

\begin{tabular}{|c|c|c|c|}
\hline Designation & Accession numbers submitted to $\mathrm{NCBI}^{\mathrm{v}}$ & Reference sequences & $\begin{array}{l}\text { Number of } \\
\text { isolates }(\%)^{\mathrm{w}}\end{array}$ \\
\hline AG-A & $\begin{array}{l}\text { HQ225636, HQ225637, HQ269815, HQ269818, } \\
\text { HQ269821, HQ269824 }\end{array}$ & 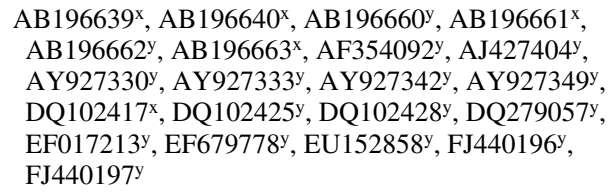 & $7(4.8)$ \\
\hline AG-G & None & AB $196646^{x}$ & $2(1.4)$ \\
\hline AG-K & HQ269808, HQ269813, HQ269822 & $\begin{array}{l}\text { AB122145 }, \text { AB196652y, AB286932y }, \text { AY927358 } \\
\text { DQ102429y, DQ279056 }\end{array}$ & $19(13.1)$ \\
\hline AG-R & HQ269817, HQ269823 & $\mathrm{AB} 219146^{\mathrm{x}}, \mathrm{DQ} 278936^{\mathrm{y}}$ & $13(9.0)$ \\
\hline AG-S & HQ269814, HQ269819 & $\mathrm{AF} 354084^{\mathrm{z}}$ & $14(9.7)$ \\
\hline AG-U (AG-P) & $\begin{array}{l}\text { HQ269809, HQ269810, HQ269811, HQ269812, } \\
\text { HQ269816, HQ269820, HQ269825 }\end{array}$ & 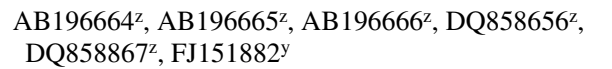 & $83(57.2)$ \\
\hline R. solani $\mathrm{AG}-2$ & HQ404661, HQ404662 & AF354116y, GU811688y & $4(2.8)$ \\
\hline Uncultured Laetisaria sp. & HQ404663, HQ404664 & DQ672336', EU622841 & $3(2.1)$ \\
\hline
\end{tabular}

${ }^{v} \mathrm{NCBI}=$ National Center for Biotechnology Information

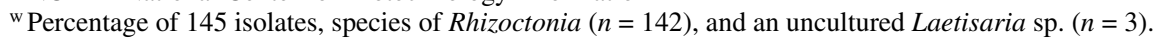

${ }^{x}$ Reference sequences from Sharon et al. (27).

${ }^{y}$ Reference sequences from GenBank.

${ }^{\mathrm{z}}$ Reference sequences from Rinehart et al. (25). 
studies are needed to identify whether nutritional preferences, favorable environmental variables such as temperature and moisture, or other biological and edaphic factors influence the high recovery frequency of Rhizoctonia fungi from leaf litter.

With the advent of molecular techniques, colony phenology is less emphasized than in the past and has never been diagnostic for AG identification. Although no one color on the reverse side of hPDA cultures was unique to a single AG, color was specific to several BNR AGs. Color on the reverse side of the culture provides a simple level of putative data for the larger number of isolates collected. Dark-brown-colored isolates comprised $75.6 \%$ of the 3,655 isolates recovered in the study. Binucleate isolates comprised $88.7 \%$ of the 604 isolates assessed for their nuclear state. Within the 145 isolates sequenced, AG-U comprised $57.2 \%$ of the 145 isolates, $60.1 \%$ of the binucleate isolates, and $77.9 \%$ of the darkbrown isolates. Although all 3,655 isolates were not assessed for the nuclear state or sequenced, AG-U traits are proportionally represented within each data profile.

The Rhizoctonia fungi recovered from azalea may be pathogens on various ornamental plant genera. The current spatial distribution pattern of Rhizoctonia fungi may involve plant genera other than azalea, and elucidation of dispersal mechanisms may need to consider a multitude of possible reservoirs at a single nursery. Control is currently limited to fungicide applications. With the extensive colonization by pathogenic BNR isolates and lack of practical control options for web blight in container-grown azalea, procedures for generating BNR-free azalea cuttings and liners is currently being investigated. The first step of this process has been accomplished. Submerging azalea stem cuttings in $50^{\circ} \mathrm{C}$ water for $21 \mathrm{~min}$ did not inhibit rooting success of 12 cultivars and eliminated Rhizoctonia AG-U from stem cuttings whereas disinfestant chemi-

Table 6. Contingency table of the frequency of anastomosis groups (AGs) of Rhizoctonia spp. recovered in 2007

\begin{tabular}{lccc}
\hline & \multicolumn{3}{c}{$\begin{array}{c}\text { Number of isolates recovered } \\
\text { (\% column total) }\end{array}$} \\
\cline { 2 - 4 } Fungal identification & February & May & June/July \\
\hline Binucleate Rhizoctonia $^{z}$ & & & \\
AG-A & $1(1.8)$ & $4(7.6)$ & $2(6.7)$ \\
AG-K & $8(14.0)$ & $9(17.0)$ & $2(6.7)$ \\
AG-R & $4(7.0)$ & $7(13.2)$ & $2(6.7)$ \\
AG-S & $6(10.5)$ & $6(11.3)$ & $2(6.7)$ \\
AG-U & $36(63.2)$ & $27(50.9)$ & $20(66.7)$ \\
R. solani AG-2 & $2(3.5)$ & $0(0.0)$ & $2(6.7)$ \\
\hline
\end{tabular}

y Pearson's $\chi^{2}$ value was 9.5254 with 10 degrees of freedom for the general association between the frequency of AG recovery and time of year recovered using the Fisher exact test $(P<0.4831)$.

${ }^{\mathrm{z}}$ Not included were two AG-G and three uncultured Laetisaria sp. isolates recovered in February and May because of low frequency values.

Table 7. Contingency table of anastomosis groups (AGs) of Rhizoctonia spp. isolated from nonsymptomatic stems, leaf litter, and pine bark growing medium (GM) of a container-grown azalea plant

\begin{tabular}{lccc}
\hline & \multicolumn{3}{c}{$\begin{array}{c}\text { Number of isolates recovered } \\
\text { (\% column total) }\end{array}$} \\
\cline { 2 - 4 } Fungal identification & Stems & Leaf litter & GM \\
\hline Binucleate Rhizoctonia & & & \\
AG-A & $2(3.3)$ & $4(7.8)$ & $1(3.4)$ \\
AG-K & $1(1.7)$ & $18(35.3)$ & $0(0.0)$ \\
AG-R & $7(11.7)$ & $1(2.0)$ & $5(17.2)$ \\
AG-S & $7(11.7)$ & $0(0.0)$ & $7(24.1)$ \\
AG-U & $41(68.3)$ & $27(52.9)$ & $15(51.7)$ \\
R. solani AG-2 & $2(3.3)$ & $1(2.0)$ & $1(3.4)$ \\
\hline
\end{tabular}

y Pearson's $\chi^{2}$ value was 46.9278 with 10 degrees of freedom for the general association for the frequency of an AG being recovered from substrate zones using the Fisher exact test $(P<0.0001)$.

${ }^{\mathrm{z}}$ Not included were two AG-G and three uncultured Laetisaria sp. isolates recovered from wood and leaves, respectively, because of low frequency values. cals and fungicides did not $(7,8)$. Many obstacles still need to be overcome to prevent azalea from being contaminated during propagation and in nurseries; however, the present study has created a foundation for subsequent advances in management practices.

\section{Acknowledgments}

We thank P. Kaufman, Biological Science Technician, for technical assistance in DNA extraction, cloning, and amplification; and L. Stringer, Biological Science Technician, for technical assistance involving plant maintenance, sampling, media preparation, culture maintenance of isolates, and DNA extraction and amplification.

\section{Literature Cited}

1. Anonymous. 2003. 2003 US National Arboretum "Web Version" of the USDA Plant Hardiness Zone Map USDA Miscellaneous Publication No. 1475. http://www.usna.usda.gov/Hardzone/

2. Bell, D. K., and Sumner, D. R. 1984. Unharvested peanut pods as a potential source of inoculum of soilborne plant pathogens. Plant Dis. 68:1039 1042.

3. Benson, D. M., and Jones, R. K. 2001. Rhizoctonia web blight. Pages 63-64 in: Diseases of Woody Ornamentals and Trees in Nurseries. R. K. Jones and D. M. Benson, eds. American Phytopathological Society, St. Paul, MN.

4. Bilderback, T. E., and Fonteno, W. C. 1987. Effects of container geometry and media physical properties on air and water volumes in containers. J. Environ. Hortic. 5:180-182.

5. Carling, D. E. 1996. Genetics of Rhizoctonia species. Pages 37-47 in: Rhizoctonia Species Taxonomy, Molecular Biology, Ecology, Pathology and Disease Control. B. Sneh, S. Jabaji-Hare, S. Neate, and G. Dijst, eds. Kluwer Academic, Dordrecht, The Netherlands.

6. Chase, A. R. 1991. Characterization of Rhizoctonia species isolated from ornamentals in Florida. Plant Dis. 75:234-238.

7. Copes, W. E., and Blythe, E. K. 2009. Chemical and hot water treatments to control Rhizoctonia AG P infesting stem cuttings of azalea. HortScience 44:1370-1376.

8. Copes, W. E., and Blythe, E. K. 2011. Rooting response of azalea cultivars to hot water treatment used for pathogen control. HortScience 46:52-56.

9. Copes, W. E., and Scherm, H. 2005. Plant spacing effects on microclimate and Rhizoctonia web blight development in container-grown azalea. HortScience 40:1408-1412.

10. Copes, W. E., and Scherm, H. 2010. Rhizoctonia web blight development on container-grown azalea in relation to time and environmental factors. Plant Dis. 94:891-897.

11. Eken, C., and Demirci, E. 2003. Identification and pathogenicity of Rhizoctonia solani and binucleate Rhizoctonia anastomosis groups isolated from forage legumes in Erzurum, Turkey. Phytoparasitica 31:76-80.

12. Frisina, T. A., and Benson, D. M. 1989. Occurrence of binucleate Rhizoctonia spp. on azalea and spatial analysis of web blight in container-grown nursery stock. Plant Dis. 73:249-254.

13. Gardes, M., and Bruns, T. D. 1993. ITS primers with enhanced specificity for basidiomycetes-application to the identification of mycorrhizae and rusts. Mol. Ecol. 2:113-118.

14. Guo, Q. Y., Kamio, A., Sharma, B. S., Sagara, Y., Arakawa, M., and Inagaki, K. 2006. Survival and subsequent dispersal of rice sclerotial disease fungi, Rhizoctonia oryzae and Rhizoctonia oryzae-sativae, in paddy fields. Plant Dis. 90:615-622.

15. Ingram, D. L., Martin, C. A., and Ruter, J. M. 1989. Heat stress of container-grown plants. Int. Plant Prop. Soc. Proc. 39:348-353.

16. Kimiharu, I., Guo, Q. Y., and Masao, A. 2004. Overwintering of rice sclerotial disease fungi, Rhizoctonia and Sclerotium spp., in paddy fields in Japan. Plant Pathol. J. 3:81-87.

17. Ko, W., and Hora, F. K. 1971. A selective medium for the quantitative determination of Rhizoctonia solani in soil. Phytopathology 61:707-710.

18. Kunieda, A. S., Alfenas, A. C., and Maffia, L. A. 2005. Survival of Rhizoctonia solani mycelia and sclerotia treated with Trichoderma spp., in Eucalyptus sp. litter. Fitopatol. Bras. 30:164-168.

19. Lambe, R. C. 1982. Web blight of ornamentals. Am. Nurseryman 155:105.

20. Manici, L. M., and Bonora, P. 2007. Molecular genetic variability of Italian binucleate Rhizoctonia spp. isolates from strawberry. Eur. J. Plant Pathol. 118:31-42.

21. Martin, C. A., and Ingram, D. L. 1993. Container dimension affects rooting medium temperature patterns. HortScience 28:18-19.

22. Masuhara, G., Neate, S. M., and Schisler, D. A. 1994. Characteristics of Rhizoctonia spp. from south Australian plant nurseries. Mycol. Res. 98:8387.

23. Matsumoto, M., and Yoshida, T. 2006. Characterization of isolates of binucleate Rhizoctonia spp. associated with strawberry black root rot complex using fatty acid methyl ester (FAME) profiles. J. Gen. Plant Pathol. 72:318322.

24. Owens, J. S., Jr., and Altland, J. E. 2008. Container height and Douglas fir bark texture affect substrate physical properties. HortScience 43:505-508.

25. Rinehart, T. A., Copes, W. E., Toda, T., and Cubeta, M. A. 2007. Genetic characterization of binucleate Rhizoctonia species causing web blight on 
azalea in Mississippi and Alabama. Plant Dis. 91:616-623.

26. Sharon, M., Freeman, S., Kuninaga, S., and Sneh, B. 2007. Genetic diversity, anastomosis groups and virulence of Rhizoctonia spp. from strawberry. Eur. Plant Pathol. 117:247-265.

27. Sharon, M., Kuninaga, S., Hyakumachi, M., and Sneh, B. 2006. The advancing identification and classification of Rhizoctonia spp. using molecular and biotechnological methods compared with the classical anastomosis grouping. Mycoscience 47:299-316.

28. Sneh, B., Zeidan, M., Ichielevich-Auster, M., Barash, I., and Koltin, Y. 1986. Increased growth responses induced by a nonpathogenic Rhizoctonia solani. Can. J. Bot. 64:2372-2378.
29. Tewoldemedhin, Y. T., Lamprecht, S. C., McLeod, A., and Mazzola, M. 2006. Characterization of Rhizoctonia spp. recovered from crop plants used in rotational cropping systems in the Western Cape Province of South Africa. Plant Dis. 90:1399-1406.

30. White, T. J., Bruns, T., Lee, S., and Taylor, J. 1990. Amplification of ribosomal RNA genes for molecular evolution studies. Pages 315-322 in: PCR Protocols: A Guide to Methods and Applications. M. A. Innis, D. H. Gelfand, J. J. Sninsky, and T. J. White, eds. Academic Press, San Diego, CA.

31. Yang, G. H., Chen, H. R., Naito, S., Ogoshi, A., and Deng, Y. L. 2005. First report of AG-A of binucleate Rhizoctonia in China, pathogenic to soya bean, pea, snap bean and pak choy. J. Phytopathol. 153:333-336. 